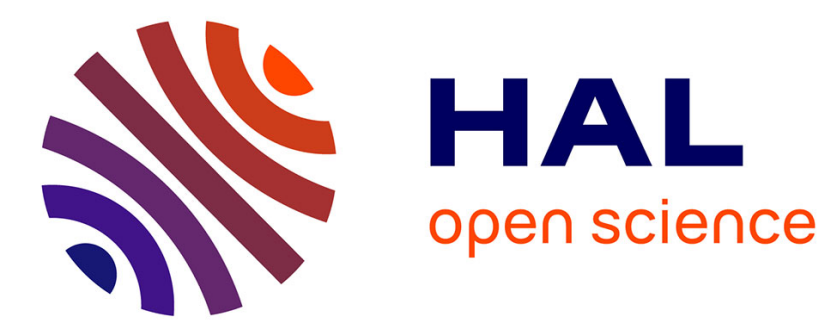

\title{
The 14UD pelletron accelerator
}

D.C. Weisser

\section{- To cite this version:}

D.C. Weisser. The 14UD pelletron accelerator. Revue de Physique Appliquée, 1977, 12 (10), pp.13031308. 10.1051/rphysap:0197700120100130300 . jpa-00244312

\section{HAL Id: jpa-00244312 https://hal.science/jpa-00244312}

Submitted on 1 Jan 1977

HAL is a multi-disciplinary open access archive for the deposit and dissemination of scientific research documents, whether they are published or not. The documents may come from teaching and research institutions in France or abroad, or from public or private research centers.
L'archive ouverte pluridisciplinaire HAL, est destinée au dépôt et à la diffusion de documents scientifiques de niveau recherche, publiés ou non, émanant des établissements d'enseignement et de recherche français ou étrangers, des laboratoires publics ou privés. 


\title{
THE 14UD PELLETRON ACCELERATOR
}

\author{
D. C. WEISSER \\ Department of Nuclear Physics \\ Australian National University, Canberra \\ Australia
}

\begin{abstract}
Résumé. - Le 14UD a évolué au cours des deux dernières années, des essais de réception vers un outil de recherche très convenable et bien adapté à la physique des ions lourds ont été faits. Le développement du système de répartition à pointe corona ouverte avec la réintroduction de fils liés a éliminé les problèmes liés au contrôle des gradiens et à la durée de vie des pointes corona. L'inspection commode des pointes ouvertes est d'une aide efficace pour établir un diagnostic lors de problèmes de transport de faisceau. Les commandes à distance électromécaniques dans le terminal ont été remplacées par des commandes pneumatiques activées par du $\mathrm{SF}_{6}$ à une pression de 50 psi au-dessus de la pression du tank. Les feuilles sont changées, les sublimateurs mis en route et le diaphragme d'ouverture du tube haute énergie sélectionné à l'aide de ces dispositifs.

Une longue expérience de conduite entre 6 et $13 \mathrm{MV}$ nous a convaincu que les pointes corona fermées n'étaient pas convenables pour notre opération. La machine est très stable avec des courants corona négligeables sur le tube ou sur la colonne. A cause de cela la machine ne fonctionne typiquement qu'avec une seule chaîne en service à la fois. Depuis l'installation de graisseurs activés au SF ${ }_{6}$ pour les chaînes, il n'y a eu aucun autre problème d'instabilité ou de décharge.

Une vanne intégrée pour le système de feuilles de stripper NEC a été installée afin de maintenir le tube en état de conditionnement lors du changement de feuilles. Tous les câbles d'alimentation de puissance ont été remplacés par des câbles isolés de matière minérale. Aucune dégradation de l'isolement n'a été observée.
\end{abstract}

Abstract. - The 14UD has evolved over the past two years from acceptance tests to an extremely reliable and convenient research tool well suited to heavy-ion physics research. The development of the open corona point distribution system with the reintroduction of tie wires eliminated problems with gradient control and point lifetime. Easy inspection of the open points is a valuable diagnostic aid when beam transport problems occur. Electromechanical remote actuators for functions in the terminal have been replaced with pneumatic ones driven by $\mathrm{SF}_{6}$ at 50 psi above tank pressure. Foils are changed, sublimer pellet heaters switched and a high energy tube entrance aperture selected by these devices.

Long experience running from 6 to $13 \mathrm{MV}$ has convinced us that enclosed corona points would not make our operation any more convenient. The machine is quite stable with negligible tube and column corona currents. Because of this, the machine typically runs with only one chain at a time. Since installation of $\mathrm{SF}_{6}$ powered oilers for the chains, there have been no further problems of instability or breakage.

An integral valve for the NEC stripper foil assembly has been installed to maintain the conditioned status of the tube during stripper foil changes. All main power wiring has been replaced with mineral insulated cable sheathed in copper. No degradation in insulation has been found.

The 14UD was installed at the ANU in Canberra from november 1972 to april 1973. Acceptance tests were performed in november 1973 and experimental work started near that time.

I will concentrate in this talk on those aspects of the development of the 14UD designed to enhance its reliability. The goal of pursuing reliability at the expense of peak operating voltage grew out of the view that it was essential to get experiments up and running as soon as possible. This view was reinforced by early experience with spark induced failures of the machine at voltages greater than $12 \mathrm{MV}$. As it turned out, this approach was in good accord with the needs of our experimenters. Undoubtedly the experimenters' evaluation of what the machine could confor- tably do affected their choice and design of experiments. More than half of machine requests in any case were for $\gamma$-ray experiments which typically require target currents of less than $50 \mathrm{nA}$ and frequently about $1 \mathrm{nA}$. Most requests, given a $12 \mathrm{MV}$, or for that matter, $14 \mathrm{MV}$ terminal, specify relatively light projectiles, e.g. oxygen and sulphur. Thus most needs could be satisfied using a higher charge state at reduced intensity, at moderate terminal voltage.

The status of the machine at the time of acceptance test was perhaps typical of any innovative accelerator, not very reliable. The four serious areas of concern which I will deal with are :

1. debilitating failures of terminal electrical equipment due to sparks above $12 \mathrm{MV}$. 
2. Tube corona point failures resulting in gradient distortions.

3. Lack of reliable vacuum pumping of the accelerator tube.

4. Trouble with the charging chains and chain breakage.

The most critical component in any heavy ion electrostatic accelerator is the ability to change stripper foils. So it was the shortcomings of this system that attracted attention early.

Table I shows the components of the original NEC supplied system. There are at least 27 electrical com-

\section{FOIL CHANGER CONTROL COMPONENTS}

\begin{tabular}{|c|c|c|}
\hline & $\begin{array}{c}\text { NEC } \\
\text { SYSTEM }\end{array}$ & $\begin{array}{c}\text { ANU } \\
\text { SYSTEM }\end{array}$ \\
\hline $\begin{array}{l}\text { LOW } \\
\text { VOLTAGE } \\
\text { END }\end{array}$ & $\begin{array}{l}\text { MOTOR, } \\
\text { SWITCH. }\end{array}$ & $\begin{array}{c}\text { SOLENOID } \\
\text { PNEUMATIC } \\
\text { VALVE }\end{array}$ \\
\hline $\begin{array}{c}\text { COMMUNICATION } \\
\text { WITH } \\
\text { TERMINAL }\end{array}$ & $\begin{array}{l}\text { LUCITE RODS, } \\
\text { COUPLINGS, } \\
\text { BEARINGS. }\end{array}$ & $\begin{array}{c}\text { NYLON TUBING, } \\
\text { BUSHES. }\end{array}$ \\
\hline $\begin{array}{l}\text { HIGH } \\
\text { VOLTAGE } \\
\text { TERMINAL }\end{array}$ & $\begin{array}{l}\text { ALTERNATOR, } \\
\text { MOTOR, } \\
4 \text { SWITCHES, } \\
3 \text { RELAYS, } \\
\text { IIIV D.C. PS., } \\
\text { ELECTRIC } \\
\text { COUNTER, } \\
\text { WIRES, } \\
\text { CABLES, } \\
\text { DIODES, } \\
\text { CAPACITORS. }\end{array}$ & $\begin{array}{c}\text { ONE TURN } \\
\text { PNEUMATIC } \\
\text { ACTUATOR, } \\
\text { MECHANICAL } \\
\text { COUNTER. }\end{array}$ \\
\hline $\begin{array}{l}\text { ELECTRICAL } \\
\text { ITEMS IN } \\
\text { PRESSURE } \\
\text { VESSEL }\end{array}$ & 23 & 1 \\
\hline
\end{tabular}

ponents. It is no exaggeration to say that just about every one of them failed at some time or other. Even alternator and rotating shaft failures, which did occur, prevented the ability to change foils. At first we just replaced all this equipment in the terminal with a series of rods coupled directly to a lucite control rod. Since there were still failures of the rod drive electronics at the low energy end, we opted for a pneumatic system based on our successful experience with one in the EN accelerator. The components list of this system is shown on the table. Three way solenoid valves deliver compressed $\mathrm{SF}_{6}$ from a bottle outside the tank, through $1 / 4^{\prime \prime}$ nylon tubes to the terminal. There the pulse of pressure powers a one turn actuator of our design. This is coupled to the quarter turn geneva mechanism supplied by NEC on the stripper assembly. Figure 1 shows the actuator on the stripper. Above and below are titanium sublimation pumps. The flexible cable from the actuator goes to a mechanical counter viewed by a TV camera through the tank wall. Figure 2 shows a disassembled actuator. As the piston is forced against the spring, a pin in the spiral scroll causes the end cylinder to rotate through $360^{\circ}$ When the pressure is released this rotation is retained.

The complete $\mathrm{SF}_{6}$ actuator system comprises

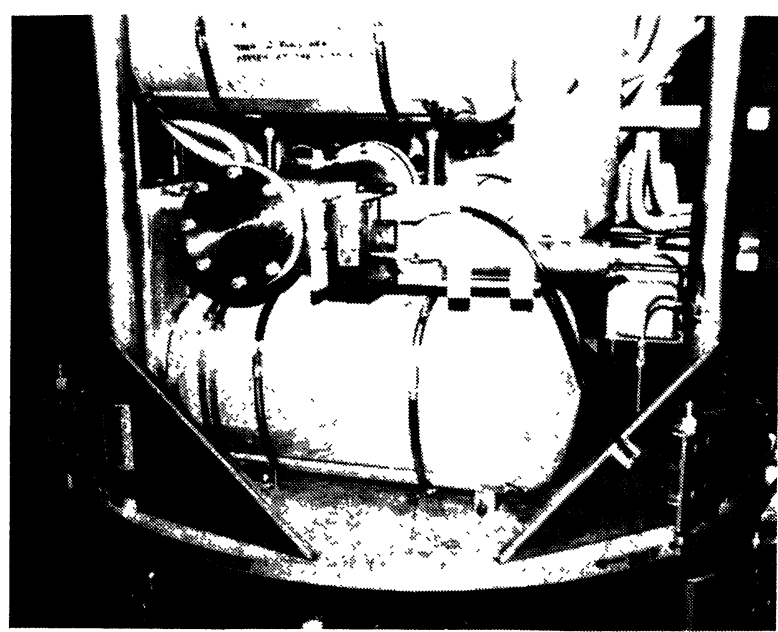

FIG. 1. - Foil stripper pneumatic actuator in the terminal.

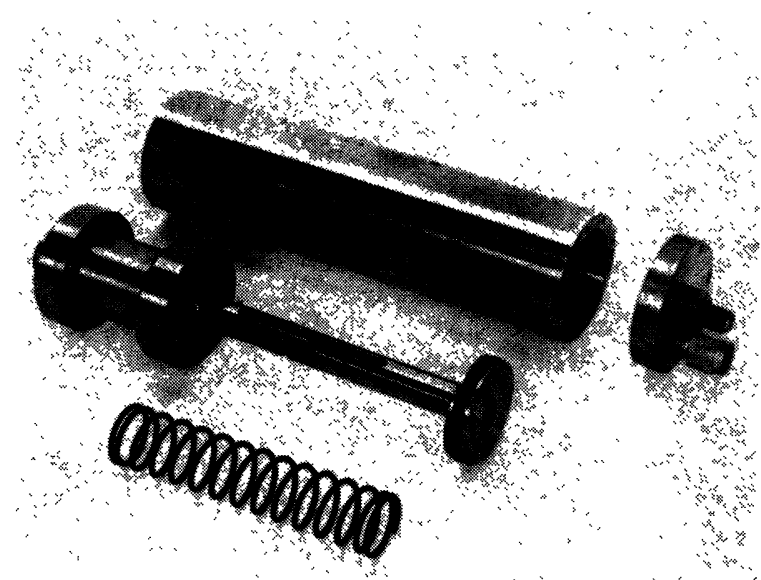

FIG. 2. - Disassembled actuator. Compressed $\mathrm{SF}_{6}$ forces the piston to the left. A pin in the spiral groove causes the end shaft to rotate through $360^{\circ}$

6 tubes, four of which are now in use. Figure 3 shows the tubes entering the casting at the high energy end. At the top and bottom surface of each casting the tubes make snug fits in rounded holes in aluminium

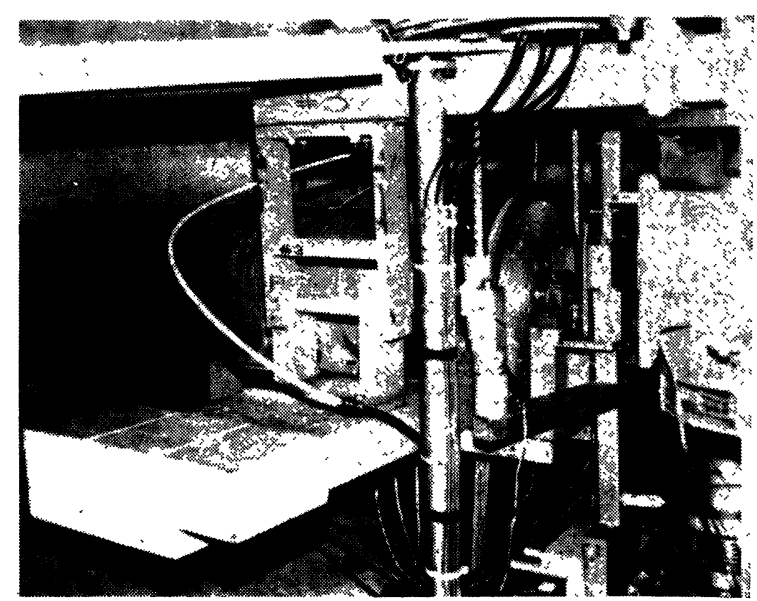

FIG. 3. - Pneumatic actuator tubes entering high energy casting through rounded bushes. 
plates. The functions now controlled are the foil charge, two sublimer selector switches for the terminal pumps and the cupature. This actuator is shown in figure 4. The cupature is a selectable aperture and Faraday cup at the entrance to the high energy tube. The beam has passed through the terminal triplet by this point. The currently unused lines are slated for our high energy stripper and to reverse direction of the terminal foil changer.

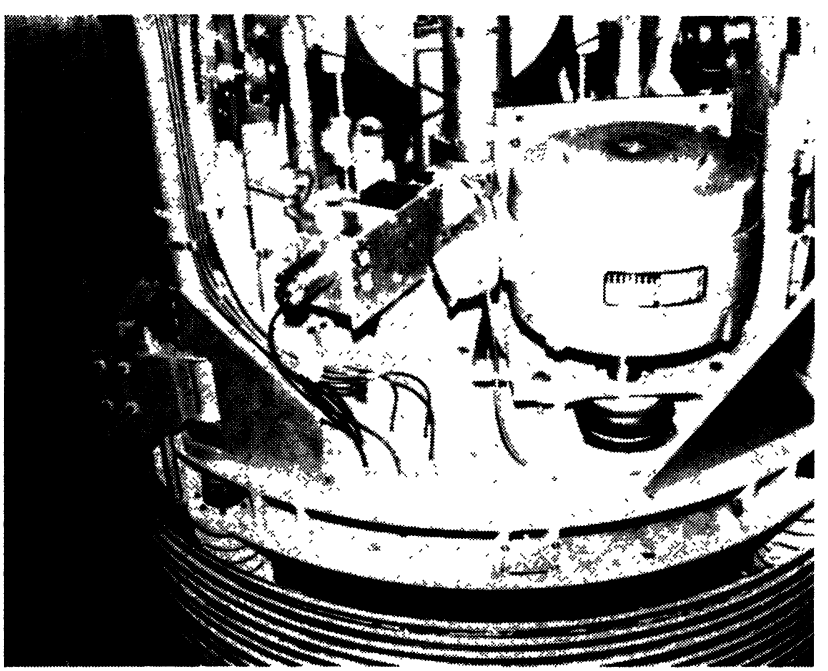

FIG. 4. - Pneumatic actuator on variable aperture at the entrance to the high energy tube.

Since failures of electrical terminal components were frequently in the mains wiring, we have now replaced all wiring with copper sheathed, mineral insulated cable, pyrotenax. The distribution box is shown in figure 5 . In our experience over more than a year there has been no failure caused by the Pyrotenax (1). We are now looking into installing lightning

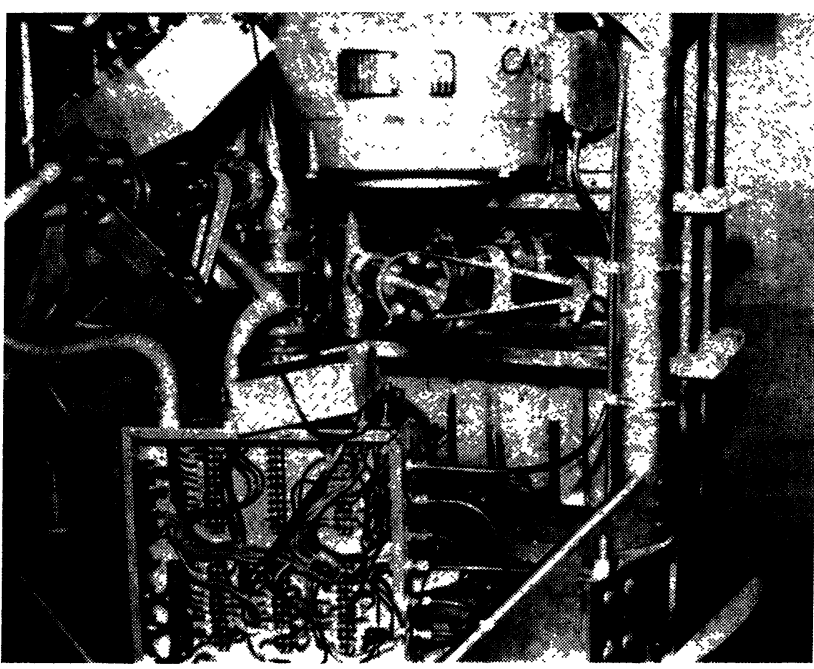

FIG. 5. - All single screened power wiring has been replaced with copper sheathed, mineral insulated cable Pyrotenax TM.

(1) Pyrotenax Australia Pty. Ltd. arrestors manufactured by the cable supplier. This type of cable is usually used on radio transmission towers subject to lightning strikes.

As you all know, pelletrons use corona point systems instead of resistors to distribute the potential along the tube and column. Figure 6 shows the system as it currently is used in Canberra. This triple-point soldered assembly replaces the original single-point

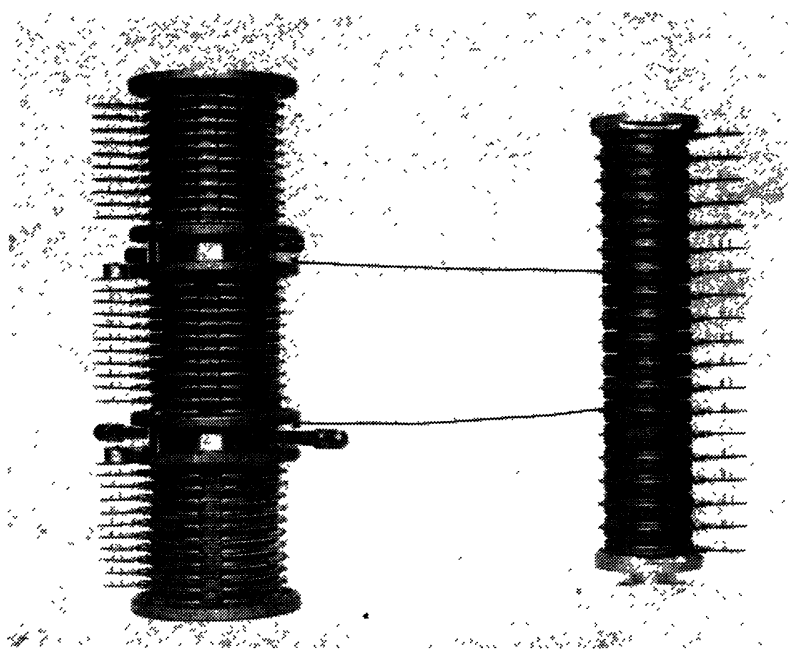

FIG. 6. -- Corona point distribution system with the wires between decoupling apertures and column.

set-screw type. Since switching to the triple type the reliability of the machine has increased greatly. This wasn't the case when this type of point was first installed. In fact as I'll soon show, we had repeated failures of tube points, especially those at the $1^{\prime \prime}$ apertures between castings. At that time the stringer wires were not present - they had been removed when the single type point was replaced with the triple. Their reintroduction was one ingredient in solving the point failure problem.

Figure 7 shows a failed point set next to a new one.

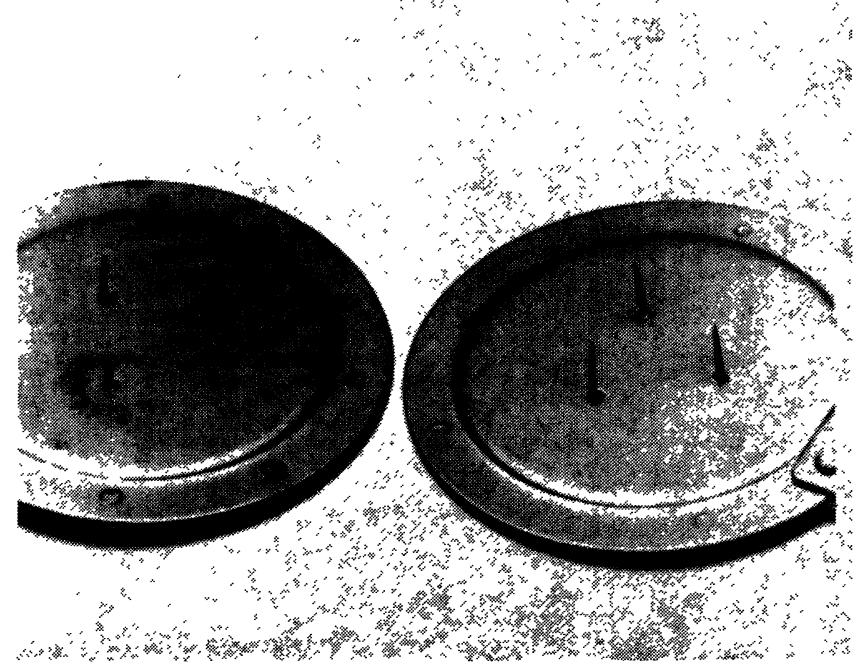

Fig. 7. - A failed tube corona point on the left next to an unused one. 
Notice the apparently melted blob on this point. NEC suggested that this type of failure is associated with high power discharges rather than continuous operation. Figure 8 shows our tube point usage record. There the advantage of exposed corona points is apparent. The lines represent the number of points in

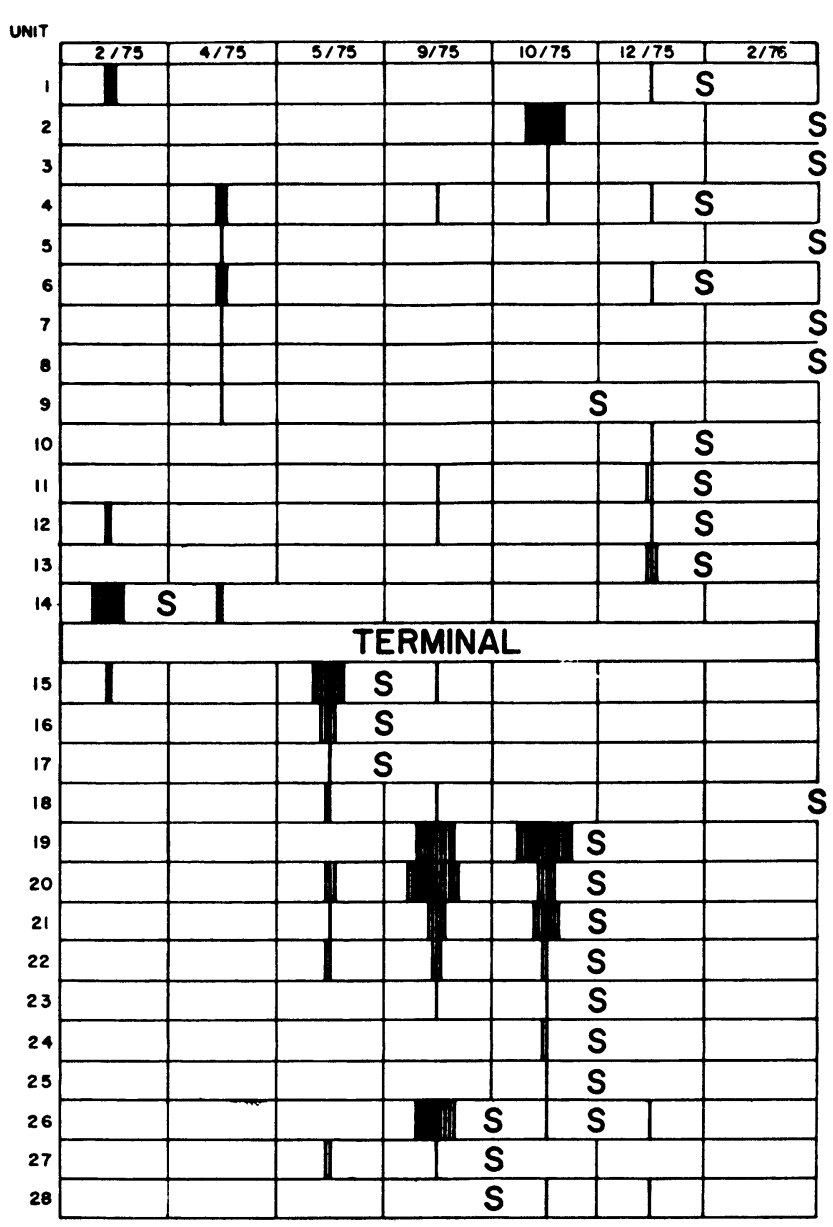

CORONA POINT FAILURES

FIG. 8. - Tube corona point use record. A single bar is for a failed corona point. The $\mathrm{S}$ is for the installation of a pair of stringer wires.

a given unit indicated at the left, that needed replacement. The $\mathrm{S}$ symbol denotes the subsequent installation of a pair of stringer wires in a unit. The failure of points up through $7 / 75$ was due to misalignment of the ion source with respect to the tank. The installation of stringer wires reduced point failure. Only the correction of the misalignment eliminated the failures. The losses in the high energy end puzzled us for quite a while. It turned out that troubles in the terminal triplet power supplies dumped beam in the HE tube causing these failures. Installation of stringer wires reduced but did not eliminate point failures. The correction of machine pathologies completely eliminated all subsequent failures. Because the pattern of point replacement resulted in very non-uniform sharpness and therefore gradient along the machine, we decided to replace all the points with a new set and complete the installation of the remaining stringer wires. For over a year now, no tube points have needed replacement. Recently a few somewhat dulled tube points were replaced in unit 15 and some column points in unit 14.

This experience provides us with a treatment but not a true understanding of what causes point failure. Why do the points at the $1^{\prime \prime}$ aperture fail preferentially? Why do stringer wires help, since they cannot cope with significant RF power in discharges, which one supposes do cause the failures.

Here let me extole the virtues of unenclosed corona points. Their ease of inspection and replacement is self evident and much appreciated. But what is of greater importance is that the arguments for enclosed points are not supported by our operational experiences. The machine copes quite well with substantial changes of terminal voltage without the need to change tank pressure. Many experiments are performed with no detectable tube or column current. The only load on the terminal is the $50 \mu \mathrm{A}$ control tube current and whatever beam load that occurs. Usually transmission in this mode is $\sim 80 \%$ of that obtained by inserting enough shorting rods to re-establish continuous tube and column currents. Exactly what happens to the classical entrance waist in the absence of these currents is a mystery to me.

For large injected beams, e.g. $>1 \mu \mathrm{A}$ oxygen, rods to short out units 2, 4, 6, 26, 27 and 28 are sometimes inserted. Such occasions are usually instigated by me rather than required by experimenters. Changes of gas pressure are even more rare. Frequently, the experimenter will choose a low charge state, say oxygen $4^{+}$, and operate at higher terminal volts.

The ability to maintain high vacuum in the accelerating tube is obviously crucial to machine performance. You may know about the addition by NEC of a midsection pump in the LE tube to reduce beam loading. This strategy has proved successful and formed the basis for the Oak Ridge design. However there was frequent trouble with the NEC hot filament ion pumps. All three installed in the machine failed immediately and those outside were frequently under repair. We have retained the NEC titanium sublimer pumps, but replaced the ionizers with $10 \mathrm{l} / \mathrm{s}$ triode ion pumps once manufactured by AEI. These have proven quite invulnerable to damage in the machine at the midsection and terminal. Another boon to leak detection and repair has been the ability to install an NRC helium spectrometer leak head in the terminal. Two long standing leaks were found with this.

We have discarded the liquid nitrogen trapped oil rotary pumps used by NEC to rough the tube in favour of an oil free system consisting of a carbon vane pump followed by a single sorption pump. This outperforms the previous system.

Originally, in order to change the foils, the accelerator tube had to let up to atmospheric pressure. This always resulted in lost time: a couple of days pump down and a couple of days reconditioning the 
machine from $10 \mathrm{MV}$. We have now installed a zero length valve that isolates the foil volume. Figure 9 shows a view through the flange on which the foil band assembly is mounted. The valve is in the closed position. Aluminium disks are forced against the knife edge ends of the two stripper tubes. The actuator rod is bellows sealed and extends to seal the valve and retracts entirely out of the beam path when withdrawn. The port leads to the stripper gas inlet and the valve used to rough out the stripper volume. Figure 10 shows the outside of the assembly with the HE stripper tube in the foreground.

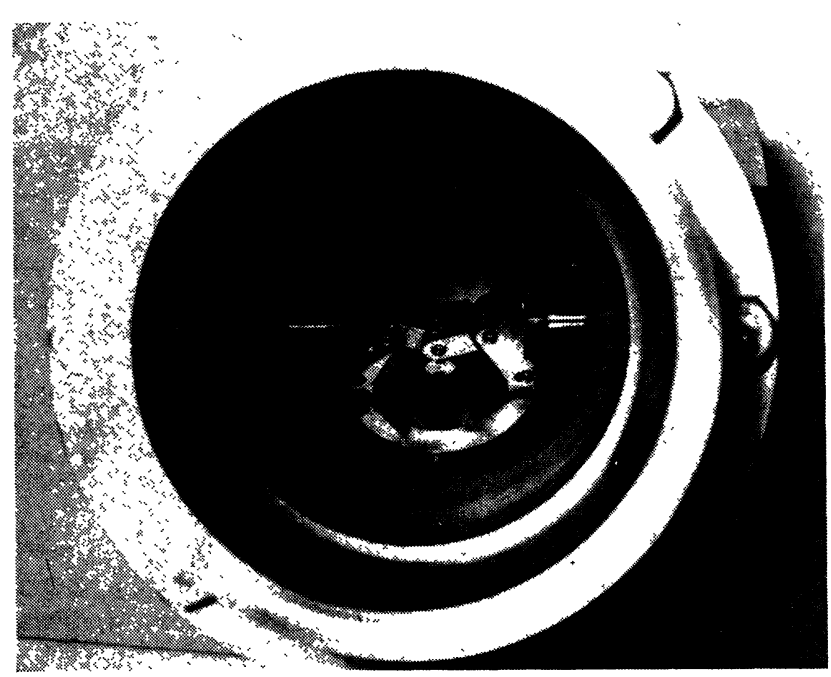

FIG. 9. - Terminal foil stripper housing. Valve is in the closed position.

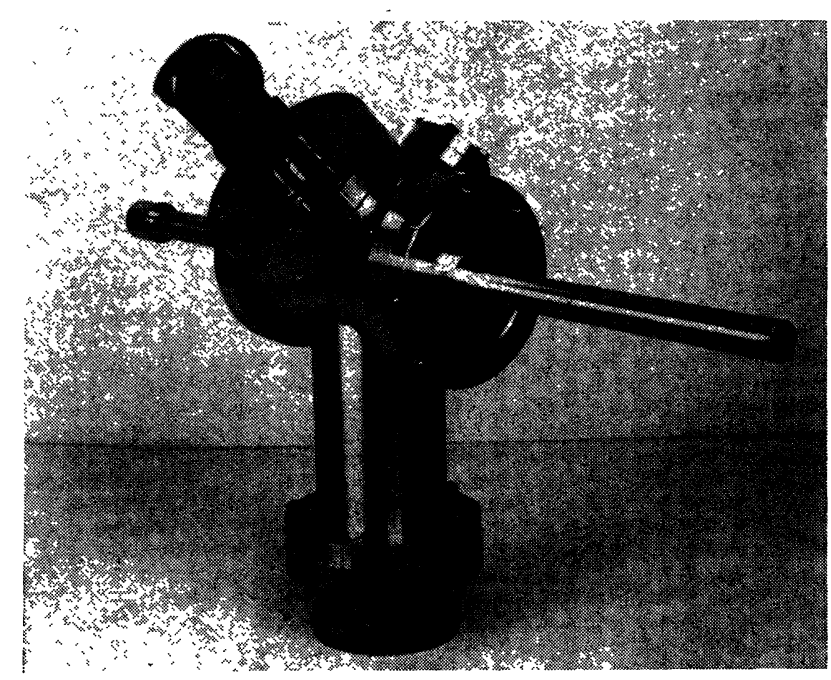

FIG. 10. - Terminal foil stripper assembly. Cam operated valve mechanism is shown.

The tube vacuum is now constantly in the $10^{-8}$ range and there is essentially no apparent loss of tube conditioning after a foil change.

Most of the improvement in the pelletron charging systems have been provided by NEC. We now use hard chrome plated pellets, flared inductors and side contact main pulleys. Our contribution has been the addition of cheap $\mathrm{SF}_{6}$ driven oilers and the observation that the right amount of oil, whatever that is, is consistent with no self charge, stably running chains, and no breakage. Figure 11 shows the oilers. A solenoid valve, external to the tank introduces a pulse of $\mathrm{SF}_{6}$ into the pipe and through the oil mister. The mist is then condensed into drops in a sintered bronze plug and allowed to drip on the main pulley. Now that this system has been installed, it is used about once a month for a 2 second burst.

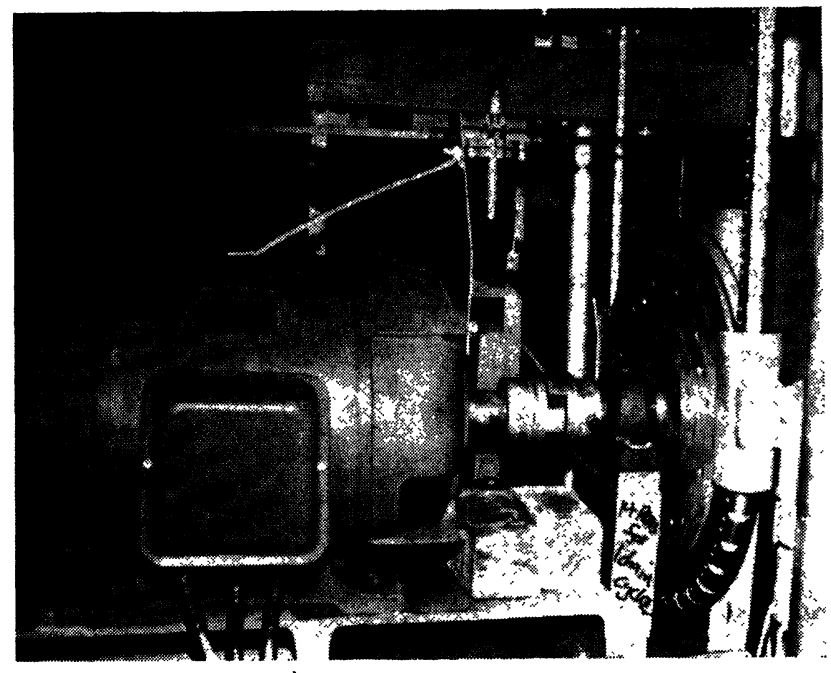

FIG. 11. $-\mathrm{SF}_{6}$ operated Pelletron oiler. Oil reservoir and sintered bronze mist condensor are shown.

Another contribution to chain longevity is the observation that it is usually only necessary to run one chain. This amply satisfies most requirements because so little current is drained along the tube and column corona points.

What are the results? Figure 12 shows a calendar of the 14UD schedule since january 1975. The dark bands are tank openings, the medium grey bands external maintenance or building requiring the accelerator off, and the light grey bands are scheduled experimental time. There has been an overall improvement in time used for experiments. Indeed for one typical set of $\gamma$-ray experiments there was no lost time over the period december 1975 to march 1977. This research will produce six publications and one $\mathrm{Ph}$.D. thesis. The last occasion when we were forced to go into the tank by a failure of a crucial component was march 1976; a chain breakage. The large block of time in october and november 1976 was for the installation of our stripper valve, the rebuilding of all the vacuum pumps and the replacement of most of the power shaft bearings. No longer is time taken up patching barely serviceable apparatus. The main effort is now going into the introduction of new or improved devices.

In 1975 and some of 1976 much of our down time was caused by the ion source. This is no longer the case. I could detail analogous set of improvements to 


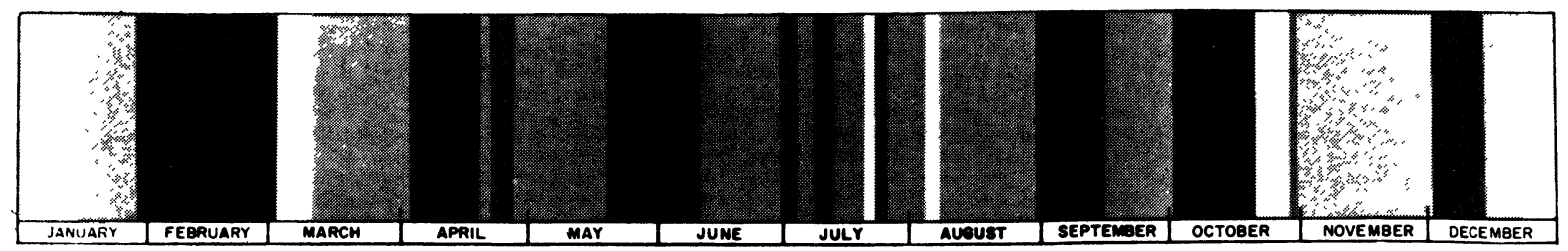

1975

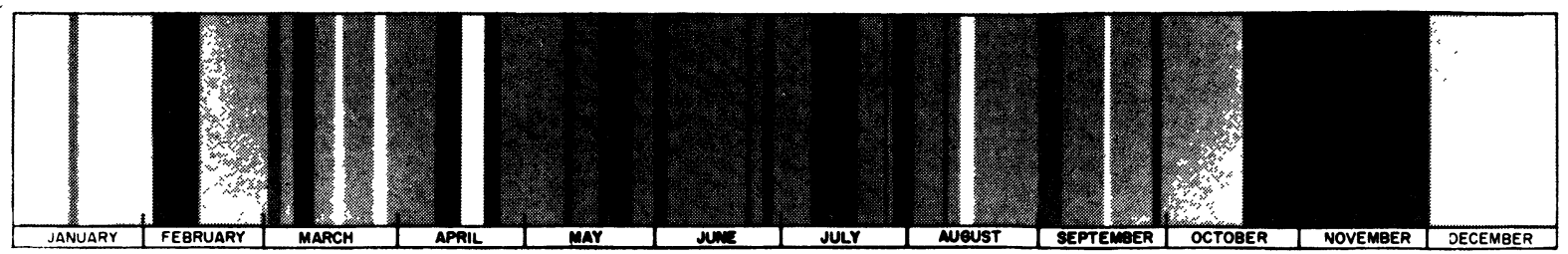

1976

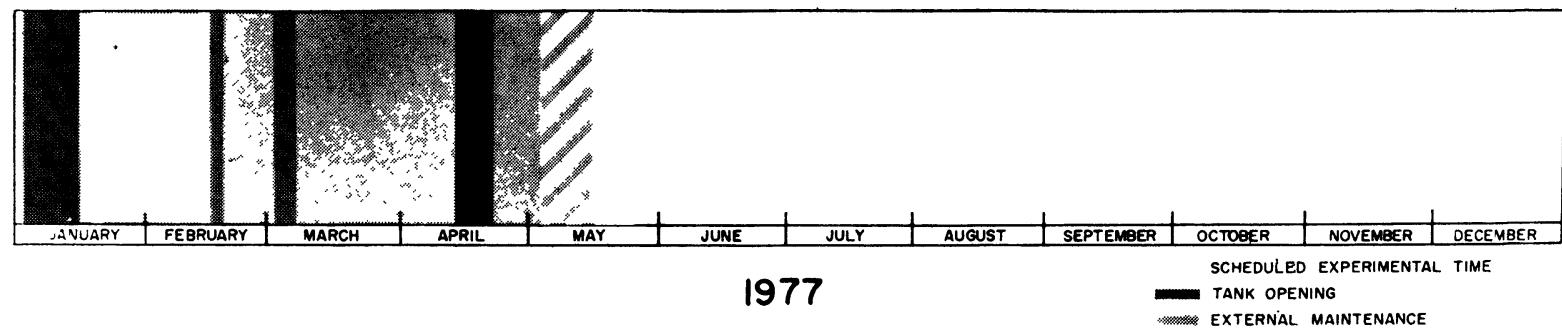

FIG. 12. - Operating calendar.

our General Ionex lithium exchange source that have resulted in filament lifetimes for oxygen of 3 days, oven lifetimes in excess of 40 days, and anode aperture lifetimes of 6 months.

It could be said that I have avoided the question of operation at $14 \mathrm{MV}$ and to some extent I have. I think the priority of doing experiments is the appropriate one. Nevertheless we are now at the stage that spar- king above $12 \mathrm{MV}$ does not knock the machine off the air and there is no apparent loss of conditioning following a tank opening. A substantial improvement became evident when we raised our normal operating tank pressure from 80 psia to 100 psia. The machine now easily achieves the $12.8 \mathrm{MV}$ that took effort before. I am confident that normal operation near $14 \mathrm{MV}$ will be commonplace by the end of 1977 . 